\title{
La crisis de la covid-19 como oportunidad política. El uso de Twitter por Santiago Abascal durante el estado de alarma en España (14 de marzo-20 de junio de 2020) ${ }^{1}$
}

\author{
The Covid-19 crisis as a political opportunity. Santiago Abascal's use of Twitter \\ during the State of Alarm in Spain (March 14-June 20, 2020)
}

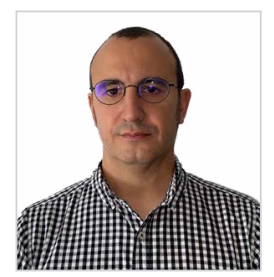

\begin{abstract}
Rubén Ramos Antón. Profesor Contratado Doctor interino en la Facultad de Comunicación de la Universidad de Castilla-La Mancha. Doctor en Información y Documentación por la Universidad de Zaragoza (2016), Máster en Periodismo de Investigación, Datos y Visualización (UNIR, 2018) y en Sociedad de la Información y el Conocimiento (UOC, 2011). Entre sus líneas de investigación se encuentra el análisis del impacto de las tecnologías de la información en la sociedad, así como los efectos de la revolución tecnológica en la información. En los últimos años ha publicado numerosos trabajos (artículos académicos, capítulos de libro, etc.) sobre esta temática. Como profesional de la comunicación ha desarrollado su carrera durante más de veinte años en diferentes medios de comunicación e instituciones (públicas y privadas) de la Comunidad Autónoma de Aragón. Grupo de Investigación Comunicación Pública: Poder, Derecho y Mensaje (COMPUBLIC).

Universidad de Castilla-La Mancha, España

Ruben.Ramos@uclm.es
\end{abstract}

ORCID: 0000-0001-7023-6463

Recibido: 02/11/2020 - Aceptado: 29/06/2021 - En edición: 16/09/2021 - Publicado: 01/12/2021 Resumen:

Los grupos políticos de extrema derecha se caracterizan por tratar de aprovechar los momentos de crisis para hacer llegar sus mensajes a la sociedad. Este tipo de partidos utiliza las redes sociales como altavoces de sus propuestas y lugar donde reclutar simpatizantes, evitando a los medios de comunicación tradicionales. En España el primer estado de alarma (entre el 14 de marzo y el 20 de junio de 2020), provocado por la covid-19, supuso una oportunidad para que Vox y Santiago Abascal multiplicaran sus críticas al gobierno y se presentaran como alternativa política. A través de una metodología cuantitativa y cualitativa, la presente investigación evalúa la forma en la que la actividad en Twitter del perfil oficial de Santiago Abascal ha logrado hacer llegar
Received: 02/11/2020 - Accepted: 29/06/2021 - Early access: 16/09/2021 - Published: 01/12/2021

\section{Abstract:}

Far-right political groups are characterized by their attempts to take advantage of moments of crisis to get their messages across to society. Parties of this type use social networks as loudspeakers for their proposals and as a place to recruit supporters, thus avoiding the traditional media. In Spain, the first State of Alarm (between March 14 and June 20, 2020), caused by covid-19, was an opportunity for Vox and Santiago Abascal to expand on their criticism of the government and present themselves as a political alternative. Using quantitative and qualitative methodologies, this study assesses how the Twitter activity of Santiago Abascal's official profile has managed to get his message across and gain more followers. To this end, the effect produced by the messages published on Santiago

1 El autor recibe financiación del Fondo Europeo de Desarrollo Regional (FEDER) convocatoria 2018/11744.

\section{Cómo citar este artículo:}

Ramos Antón, R. (2021). La crisis de la covid-19 como oportunidad política. El uso de Twitter por Santiago Abascal durante el estado de alarma en España (14 de marzo-20 de junio de 2020). Doxa Comunicación, 33, pp. 75-98. https://doi.org/10.31921/doxacom.n33a993 
su mensaje y conseguir más adeptos. Para ello se ha analizado el efecto producido por los mensajes publicados en el perfil de Santiago Abascal durante el estado de alarma en España, comparándolo con el del resto de líderes políticos españoles. Los resultados muestran que los seguidores de Santiago Abascal son los que se manifiestan más activos a la hora de interactuar con los mensajes publicados en su perfil, de un modo muy superior al del resto de líderes políticos.

\section{Palabras clave:}

Vox; coronavirus; covid-19; Twitter; Santiago Abascal.
Abascal's profile during the state of alarm in Spain has been analysed, comparing it with that of the other Spanish political leaders. The results show that Santiago Abascal's followers are the most active in interacting with the messages published on his profile, far more than other political leaders.

\section{Keywords:}

Vox; coronavirus; covid-19; Twitter; Santiago Abascal.

\section{Introducción}

\subsection{La crisis del coronavirus}

El 11 de marzo de 2020 la Organización Mundial de la Salud (OMS) declaraba la pandemia mundial provocada por el nuevo coronavirus covid-19 que fue detectado por primera vez en Wuhan (China) unos meses antes (Arroyo, 2020). A lo largo del presente siglo se han detectado tres epidemias (SARS, MERS y SARS-cov-2, más conocido como covid-19) que han afectado al ser humano y cuyo origen ha sido un coronavirus llegado a los humanos a través de la zoonosis (Latif; Mukaratirwa, 2020). A diferencia de las dos enfermedades anteriores, la covid-19 se ha extendido rápidamente por todo el mundo, afectando a millones de personas y habiendo provocado en marzo de 2021 más de dos millones y medio de muertes (Johns Hopkins, 2021). Aunque pueden variar en cada caso, los principales órganos afectados por esta enfermedad son los pulmones, el corazón, los riñones, el hígado, los intestinos y el cerebro (Kumar; Doshi; Khan; Rathore, 2020).

El escenario de una posible pandemia con consecuencias imprevisibles para el ser humano ya había sido anticipado desde hacía años por la comunidad científica (Williams, 2014), que también señalaba los efectos que podía causar en un mundo interconectado (Cooper, 2006).

A pesar de estas previsiones, la llegada de esta pandemia, además de una evidente crisis sanitaria, ha sacudido las estructuras del mundo, provocando cambios prácticamente en todos los ámbitos de la vida, tanto a nivel psicológico o social (Saladino; Algeri; Auriemma, 2020), como de conducta (Keddell; Bedoe, 2020) y especialmente sobre la planificación de la salud pública (White, 2020). A nivel económico las consecuencias se prevén catastróficas, llegando incluso a poder provocar una contracción de la economía a escala global en un 3\% (IMF, 2020). La pandemia y el confinamiento, utilizado en muchos países para combatirla, se han dejado sentir de un modo notable en sectores económicos tan importantes como el automovilístico o el turismo (Nayak et al., 2021).

Aparte del aspecto sanitario y económico, la crisis generada por el coronavirus también ha tenido un eco en el ámbito de la comunicación, con algunos efectos de los que no se tenían precedentes en los últimos años. La aparición y difusión de las teorías de la conspiración (Olesky et al., 2021) o la "cultura del miedo", que se ha mostrado en niveles de temor superiores a las experiencias negativas reales (Gruchola; Sławek-Czochra, 2021) suponen algunas distorsiones importantes que han dificultado o condicio- 
nado el proceso comunicativo. Esta situación se ha apreciado de forma clara en España, uno de los países con mayor número de fallecidos por causa de esta enfermedad en el mundo ${ }^{2}$, donde el manejo de la crisis puso en evidencia numerosos errores, como la ausencia de un anuncio temprano o la adopción de un modelo de portavocía que no contribuyó a tranquilizar a la opinión pública (Costa-Sánchez; López-García, 2020).

A pesar de las advertencias realizadas por la comunidad científica, la crisis parece haber sorprendido a la mayor parte de la opinión pública mundial, incluida a la clase política, que en muchos países ha convertido la pandemia en un asunto más de controversia y de debate. Las decisiones tomadas en torno a la gestión de la epidemia han generado polémica en diferentes países, como Brasil (Conde, 2020), Reino Unido (Tomkins, 2020) o Estados Unidos (Agnew, 2020; Tollefson, 2020).

En este estudio nos centramos en España, donde la situación vivida ha servido para enfrentar todavía más a la clase política, reforzando en las redes sociales la posición de uno de sus actores más controvertidos: el partido político de ultraderecha Vox.

\subsection{Vox como actor político}

En el caso español, después de varios años de inestabilidad política, sucesivas elecciones generales y un ambiente enrarecido, las consecuencias de la crisis sanitaria han abierto un nuevo foco para la polémica. El partido político Vox, actualmente tercera fuerza política del arco parlamentario, ha desarrollado una dura oposición a las medidas adoptadas por el gobierno español a lo largo de la crisis. Especialmente activo se ha mostrado en Twitter, hasta el punto de que ha multiplicado su visibilidad en dicha red social. Este partido ha sido clasificado como de ultraderecha, más concretamente como de derecha radical, por estudios como el de Ferreira (2019), a partir del análisis de siete características doctrinales (nacionalismo, nativismo, autoritarismo, antidemocracia, populismo, valores tradicionales y neoliberalismo). Rinken (2019, p. 73), por su parte, cataloga a este fenómeno político como "ultranacionalista".

Las situaciones de crisis, especialmente económicas, ofrecen de forma habitual una ventana de oportunidad para los partidos de extrema derecha (Antón-Mellón; Hernández-Carr, 2016; Virdee; McGeever, 2017; Mondon; Winter, 2019). De hecho, la crisis económica de 2008 ya supuso una profunda transformación en muchos países de la Unión Europea, que vino acompañada del auge de nuevos actores políticos (Gould, 2019; Van-der-Walt, 2019; Zuk; Toporowski, 2020). En los últimos años los grupos políticos de la extrema derecha han pasado de situarse en los márgenes a ocupar una posición central en el debate político (Acha-Ugarte, 2018), con capacidad de marcar la agenda e influir en la opinión pública. Un proceso que ha coincidido durante el cambio de milenio con la profundización del discurso populista de este tipo de partidos (Akkerman; De-Lange; Rooduijn, 2016, p. 48) y que la integración europea ha facilitado en el continente (Caiani, 2019), de manera que el auge de estas formaciones responde a dinámicas comunes, favorecidas por la transnacionalización de las organizaciones de la derecha radical. A pesar de que la agenda común de estos partidos resulta escasa, prácticamente reducida al discurso antiinmigración y la interpretación "nativista" de la economía (Froio \& Ganesh, 2019), lo cierto es que la cooperación transfronteriza de la extrema derecha ha espoleado el crecimiento del nacionalismo extremo en el continente (Whine, 2017, p. 330).

2 A 7 de marzo de 2021 la cifra total de fallecidos a causa de la covid-19 en España, según el registro de la Johns Hopkins University, ascendía a 71.138, siendo el décimo país del mundo con mayor número de decesos. Disponible en http://bit.ly/3qpcdi6 
En el caso de España, este tipo de partidos habían permanecido en la marginalidad desde la aprobación de su constitución, en 1978. La única excepción había sido la de la coalición Unión Nacional, que en 1979 había logrado un acta de diputado (Blas Piñar), que obtuvo más de 378.000 votos (un 2,11\% del total) (Ministerio del Interior, 2020). Sin embargo, tras varios años de mayoría absoluta del Partido Popular (de 2011 a 2015), la opción hegemónica de la derecha española hasta el momento, surge Vox como alternativa desde posiciones más extremas.

A pesar de que en sus primeras convocatorias electorales los resultados fueron testimoniales: 0,25\% en las elecciones generales de diciembre de 2015 y 0,20\% en las de junio de 2016 (Ministerio del Interior, 2020), en poco tiempo se convertirá en el tercer partido con representación parlamentaria. El punto de inflexión tendría lugar en diciembre de 2018, fecha en la que el partido entró en el Parlamento de Andalucía con doce escaños (396.607 votos, un 10,96\% del total) (Junta de Andalucía, 2018). El ascenso fulgurante se vería confirmado en las sucesivas elecciones que se produjeron a lo largo del año 2019: generales de abril (24 diputados), elecciones municipales, autonómicas y europeas de mayo y, sobre todo, en las generales de noviembre: Tercera fuerza política, con 52 escaños, 3.640.063 votos (un 15,09\%) (Ministerio del Interior, 2020).

Varias son las causas que hicieron posible el ascenso del partido entre 2016 y 2018 . Entre uno y otro momento se produjeron numerosos episodios de corrupción política, que explotaron con la sentencia del caso Gürtel, lo que catapultó la moción de censura contra el ejecutivo de Mariano Rajoy. Autores como Moreno (2020) señalan que el Partido Popular había sido ejemplo de prácticas en las que se conectaba el mundo político con el sector de la construcción, lo que originó numerosos casos de corrupción. Otros acontecimientos que coincidieron en el tiempo fueron la explosión del movimiento feminista, especialmente tras la huelga general del 8 de marzo de 2018, el continuo debate sobre la inmigración y, sobre todo, la escalada de tensión política en Cataluña. Todas estas son cuestiones sobre las que los dirigentes de Vox se han prodigado en el debate público, con posiciones alejadas de lo que el partido denomina peyorativamente consenso progre (Vox, 2020).

Estudios recientes apuntan a que el impulso electoral a Vox tuvo más que ver con el reforzamiento de la identidad nacional española (Gould, 2019; Turnbull-Dugarte, 2019). El asunto nacional frente a los enemigos externos (globalización, Unión Europea) y, sobre todo, internos (nacionalismos periféricos). El discurso antiinmigración no sería tan patente entre sus simpatizantes o seguidores (Rinken, 2019, p. 80), algo que contrastaría con lo ocurrido en otros países, donde también se ha constatado el crecimiento de partidos de extrema derecha (Van-der-Brug; Fennema, 2003; Gallego, 2017; Edo; Öztunc; Poutvaara, 2019; Hansen; Clemens, 2019; Hutchins; Halikiopoulou, 2019; Bialasiewicz; Stallone, 2020; Cheung-Blunden, 2020; Roupakias; Chletsos, 2020). Discursos que, no obstante, el partido ha lanzado, en un rasgo común que lo relaciona con otras organizaciones de corte similar en el continente, así como con el denominado efecto Bannon, que implica la promoción de ciertos puntos de vista sobre la nación, la inmigración, la Unión Europea o los musulmanes (Gould, 2019).

Tras las elecciones de noviembre, una vez constituido el actual gobierno de España, el partido elevó el tono de sus críticas ante un ejecutivo al que calificó de "ilegítimo basado en la mentira" (EFE, 2020), del que formarían parte todos los "enemigos de España" (La Razón, 2019; Europa Press, 2020). 


\subsection{Redes sociales y Vox}

Con su popularización, las redes sociales se han convertido en un nuevo escenario para la disputa política, utilizada por las organizaciones de extrema derecha y populistas de forma estratégica para hacer virales sus mensajes en la sociedad (Pérez-Curiel, 2020). Un entorno que favorece reducir cuestiones complejas a mensajes cortos (Ott, 2017; Evolvi, 2019). Esta simplicidad en los mensajes también es objeto de crítica por quienes consideran que dificulta un conocimiento profundo y elaborado. Así, Frommer (2011) se refiere al "pensamiento Power Point" y Serrano (2013, p, 131) alerta sobre los efectos de unas redes sociales que priman el exhibicionismo y la vanidad sobre la formación o el debate intelectual.

Las plataformas de redes sociales, no obstante, han conseguido tener un impacto en la agenda setting, así como un escenario para la construcción y el mantenimiento de las imágenes de los candidatos (Campos-Domínguez, 2017; Enli, 2017). Estas plataformas o canales de comunicación suponen una oportunidad para los partidos políticos, que tradicionalmente necesitaban partidarios donde predominaba la comunicación cara a cara, pero que como recuerda Norris (2007, p. 219) dejan de necesitar "trabajadores de base" donde existen múltiples canales de comunicación electrónica para lograr maximizar su apoyo electoral.

Los líderes populistas han encontrado en las redes sociales una herramienta donde sus seguidores se agrupan, en un entorno de mayor cercanía ideológica (Boulianne, Koc-Michalska; Bimber, 2020), de este modo, suponen una suerte de refugio ante los ataques dialécticos que pudieran sufrir a nivel público. Pariser (2011) en los primeros años del desarrollo de las redes sociales se refiere a los "filtros burbuja", que propician un acceso a la información acorde a los intereses de cada usuario. Estos fenómenos han sido objeto de estudios a través del análisis del comportamiento de los algoritmos, que proceden al filtrado de la información accesible a través de las redes sociales (Berman; Katona, 2019) o que proponen alternativas para superar la atomización de contenidos y mensajes (Matakos; Tu; Gionis, 2020).

El uso de las redes sociales ha resultado determinante en algunos acontecimientos políticos desarrollados en los últimos años. Elecciones presidenciales en Estados Unidos (Francia, 2017; Groshek; Koc-Michalska, 2017; Rodríguez-Andrés, 2018) o el referéndum del Brexit en el Reino Unido (Usher; Dondio; Morales, 2019) son un buen ejemplo. En este último caso, las redes sociales fueron utilizadas de forma especial por los partidos euroescépticos, cuyos discursos cargaban contra "elites" y "migrantes" (Bennett, 2019). Los comportamientos en este nuevo ámbito de comunicación y relación también se han visto rodeados por la sospecha de utilización de perfiles falsos, también denominados bots, un asunto que asimismo ha sido motivo de estudio (Howard; Woolley, Calo, 2018; Bastos; Mercea, 2019).

Durante el año 2019, en España el 59\% de la población utiliza Internet para participar en las redes sociales (Eurostat, 2020). Se trata de un nivel de uso que se sitúa en el segmento medio/bajo de los países europeos, alejado de los niveles que se registran en Islandia o Noruega (92 y 86\% respectivamente), aunque con una incidencia superior a países como Alemania (53\%), Francia (42\%) o Italia (42\%). En abril de 2020 se estima que el número de cuentas o perfiles de twitter activos en España alcanza los 8,4 millones (Statista, 2020).

En sus años de existencia, Vox ha sabido explotar su presencia en las redes sociales, siguiendo los ejemplos de otros partidos o líderes populistas o de extrema derecha, como es el caso de Salvini y la Liga Norte en Italia (Padovani, 2018; Berti, 2020), Alianza por Alemania (Darius; Stephnay, 2019; Ahmed; Pisoiu, 2020) o la extrema derecha sueca (Åkerlund, 2020), entre otros (Froio \& Ganesh, 2019). Coincidiendo con su entrada en el parlamento autonómico de Andalucía (diciembre de 2018), el partido se con- 
virtió en el eje central de la campaña electoral (Rivas-de-Roca; García-Gordillo; Bezunartea-Valencia, 2018) y para ello fue muy importante su actividad en Twitter.

El uso de las redes sociales se manifiesta como un asunto estratégico para el partido, como forma de hacer llegar su mensaje al gran público sin tener que pasar por los medios de comunicación (Pérez-Curiel, 2020), con los que no siempre mantiene una buena relación (Europa Press, 2019).

La cuenta oficial de Twitter del partido se vio envuelta durante el año 2020 en varias polémicas, llegando a ser suspendida en el mes de enero por incitación al odio (EFE, 2020b). Su actividad a lo largo de la crisis del coronavirus ha sido particularmente intensa, no estando también exenta de polémicas (Marcos, 2020).

\subsection{El papel del líder: Santiago Abascal}

Si bien el primer presidente del partido fue Alejo Vidal-Quadras (Lázaro, 2014), desde el inicio de la actividad de Vox, el partido ha pivotado en torno a la figura de su actual líder: Santiago Abascal. Cumpliendo así con una de las características de los nuevos movimientos populistas: la aparición del fundador del partido como un "líder salvador" o carismático (Rodríguez-Jiménez, 2006; Eatwell, 2007).

En este caso, además, Abascal aparece como el impulsor del proyecto político tras abandonar el Partido Popular, después de una dilatada carrera en él (Quintero; Alonso, 2014). Desde el inicio, por lo tanto, se asocia el partido al liderazgo de su impulsor. En ese sentido, Twitter ofrece un espacio adecuado para la promoción de este tipo de comportamientos, donde los sentimientos se mezclan con las formas de pensar y actuar (Kissas, 2019). En este caso, la elección del medio para lanzar mensajes durante una crisis resulta tan importante como el propio mensaje (Michailidou, 2017, p. 244).

La presencia de Santiago Abascal destaca de un modo especial en Instagram, red social en la que el político de Vox es el líder español con más seguidores $\left(787.000^{3}\right)$, con más del doble que Pablo Iglesias, el segundo. El uso que Abascal hace de su perfil de Instagram tiene que ver con la promoción de su agenda, donde abundan imágenes sin editar en la que predomina su persona, normalmente en solitario (Sampietro; Sánchez-Castillo, 2020). Este tipo de utilización de la imagen redundaría, por lo tanto, en el desarrollo de la idea del líder carismático, apuntada con anterioridad.

El liderazgo de Abascal en Instagram contrasta con su perfil de Twitter, en el que el número de seguidores es sensiblemente inferior.

3 Datos a 12 de marzo de 2021 
Tabla 1. Número de seguidores de los perfiles oficiales de los principales políticos españoles en Twitter (a 12 de marzo de 2021$)$

\begin{tabular}{|c|c|}
\hline Político & Número de seguidores en Twitter \\
\hline Pablo Iglesias (Podemos) & 2.642 .813 \\
\hline Pedro Sánchez (PSOE) & 1.558 .472 \\
\hline Albert Rivera (Ciudadanos) & 1.226 .052 \\
\hline Inés Arrimadas (Ciudadanos) & 697.434 \\
\hline Santiago Abascal (Vox) & 564.616 \\
\hline Pablo Casado (Partido Popular) & 528.117 \\
\hline
\end{tabular}

Fuente: Twitter. Elaboración propia

El perfil de Twitter de Santiago Abascal, sin embargo, experimentó una importante actividad durante el desarrollo del estado de alarma, desde donde se canalizaron sus críticas al gobierno español, lo que ha motivado la realización de este estudio.

\section{Metodología}

La presente investigación tiene por objetivo conocer la forma en la que el perfil de Twitter de Santiago Abascal se ha comportado durante el primer estado de alarma provocado por la pandemia de la covid-19 (vigente en España del 14 de marzo hasta el 20 de junio de 2020).

Partiendo del hecho de que las situaciones de crisis son utilizadas por los grupos políticos de extrema derecha para tratar de lanzar sus mensajes y ganar adeptos en la sociedad, se pretende conocer la forma en la que el líder de Vox ha utilizado como "ventana de oportunidad" la declaración del estado de alarma de marzo de 2020. El desarrollo de esta crisis se considera relevante puesto que fue la segunda vez desde la aprobación de la Constitución española (1978) en la que se recurre a esta situación excepcional. La anterior declaración afectó exclusivamente al funcionamiento de los aeropuertos y se prolongó durante 43 días (Aba, 2011). Tanto las circunstancias que han acompañado a este segundo estado de alarma, su duración (98 días) y el propio clima político en el que se ha desarrollado ofrecen una interesante perspectiva para analizar el modo en el que Vox, una opción política de carácter populista, ha utilizado las redes sociales para hacer llegar sus mensajes y multiplicar sus adeptos.

Para ello la presente investigación plantea los siguientes objetivos:

O1: Conocer la evolución del perfil de Twitter de Santiago Abascal en cuanto a actividad y número de seguidores durante el primer estado de alarma de 2020.

O2: Identificar las claves de la comunicación desarrollada por Santiago Abascal en su perfil de Twitter durante el primer estado de alarma de 2020 .

Para realizar la investigación se parte de una doble metodología (cuantitativa y cualitativa). Desde el punto de vista cuantitativo, se analiza el comportamiento de los perfiles oficiales en Twitter de los principales políticos españoles, descargando todos los mensajes que estos produjeron durante el estado de alarma. Los perfiles analizados son los de Pedro Sánchez (@sanchezcastejon), Pablo Casado (@pablocasado_), Santiago Abascal (@Santi_ABASCAL), Pablo Iglesias (@PabloIglesias) e Inés Arrimadas (@ 
InesArrimadas). En concreto, se analizan los mensajes originales escritos en ellos, quedando fuera del análisis los mensajes de otros perfiles que son compartidos por estos.

Las variables analizadas en el estudio cuantitativo son las siguientes:

1. Número de tuits publicados a lo largo del estado de alarma.

2. Popularidad de los mensajes enviados: Estudio de las reacciones positivas (favs y retuits) de los mensajes publicados en las cuentas oficiales de los políticos.

3. Comportamiento del seguimiento de los perfiles de Twitter: evolución en el número de seguidores en el periodo analizado.

En el estudio cualitativo se analiza el contenido de todos los mensajes publicados por Santiago Abascal en su perfil de Twitter (@ Santi_ABASCAL) con arreglo a las siguientes variables:

1. Temas abordados

2. Tipo de lenguaje utilizado

El periodo de análisis corresponde al primer estado de alarma de 2020, desde el momento en el que este se anuncia (en la tarde del 14 de marzo de 2020) por parte del presidente del gobierno, Pedro Sánchez, hasta su finalización (a las 23:59 horas del 20 de junio).

\section{Resultados cuantitativos}

\subsection{Actividad del perfil}

Del 14 de marzo al 20 de junio Santiago Abascal publicó en su perfil de Twitter un total de 289 mensajes, a razón de 2,9 por día. La producción de tuits del líder de Vox se situó por debajo de la de Pablo Casado (465 mensajes, 4,6 por día) y Pedro Sánchez (294, 2,9). Asimismo, Abascal registró más mensajes en esta red social que Pablo Iglesias (249, 2,5/día) e Inés Arrimadas (227, 2,2/ día). En el caso de la lideresa de Ciudadanos, su actividad en Twitter descendió considerablemente a partir del mes de mayo, momento en el que dio a luz. En las últimas semanas del confinamiento se dedicó más a compartir mensajes de otros líderes políticos o de su organización en lugar de producir los suyos propios.

La actividad del perfil de Santiago Abascal se sitúa en un término medio con respecto al resto de líderes políticos españoles, si bien experimentó algunos picos o momentos en los que resultó más intensa. 
Gráfico 1: Evolución de la producción de tuits del perfil de Santiago Abascal durante el estado de alarma (del 14 de marzo al 20 de junio de 2020) con respecto a la del resto de líderes políticos

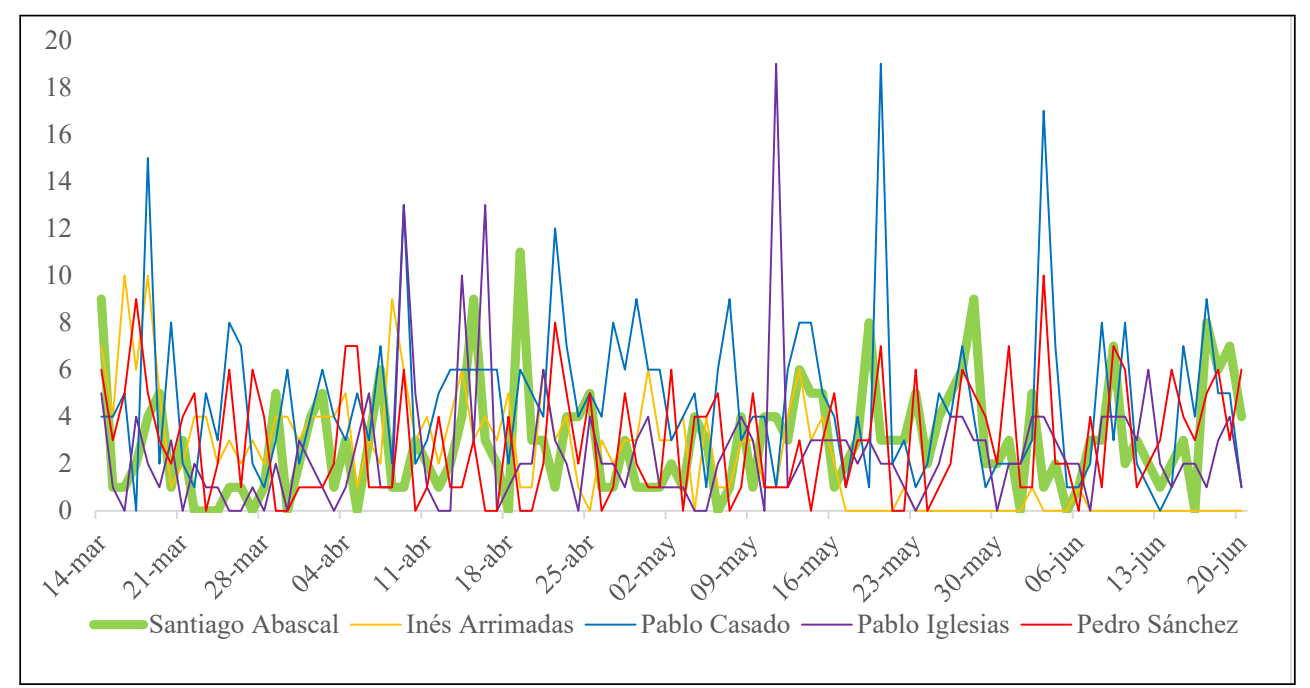

Fuente: Twitter. Elaboración propia

El día que registró una actividad más intensa fue el 19 de abril (11 mensajes). Ese día se desató una importante polémica en España por las declaraciones del Jefe del Estado Mayor de la Guardia Civil, José Manuel Santiago, en las que aseguró que las fuerzas de seguridad estaban trabajando para "minimizar el clima contrario a la gestión de crisis por parte del Gobierno" (Ortega-Dolz; González, 2020). Nueve de los once mensajes de la jornada tienen que ver con la polémica y en ellos el líder del partido clama contra las manifestaciones del guardia civil. Habla de "Alerta democrática" y además de anunciar acciones legales hace un llamamiento a los "españoles", acusando al gobierno de haber "dejado morir a miles de personas por su negligencia y sectarismo" $(\mathrm{ID}=45)$. Se trata de un buen ejemplo de actuación en el que se aprovecha un momento de crisis (unas desafortunadas declaraciones) para arremeter contra el gobierno e intentar conseguir rédito político.

Los siguientes días con más mensajes ( $n=9)$ fueron el 14 de marzo, 15 de abril y 28 de mayo. El 14 de marzo se declaró el estado de alarma y la mayor parte de los tuits tenían una intención de colaboración con esta decisión, si bien también se aprovechaba en ellos para atacar a los socios del gobierno: "Es aterrador ver al gobierno paralizado por la rapiña separatista y las ansias comunistas" (ID=5).

En cuanto al 15 de abril coincidió con una sesión de control al gobierno. Ese día denunció que la práctica parlamentaria le impedía interpelar al presidente del ejecutivo. En sus mensajes criticó duramente al vicepresidente, Pablo Iglesias: “Nadie diría que es el vicepresidente comunista y chavista que ataca a la monarquía parlamentaria y a la convivencia mientras entierra a más de 20.000 compatriotas" (ID=76). 
El 28 de mayo la mayor parte de los nueve mensajes se dedica a contestar a Pablo Iglesias, quien en la comisión de reconstrucción del Congreso acusó a Vox de "querer dar un golpe de estado" pero de "no atreverse" (Cruz, 2020). El tono en este caso también es muy agresivo, llegando a calificar a Iglesias de "vicepandemias", en un claro intento de asociar la gestión del Vicepresidente segundo del Gobierno con los efectos de la pandemia en España: "El vicepandemias sabe que su horizonte es negro como la toga de un fiscal. Y para evitar a la justicia es capaz de todo, incluido una alianza con todos los enemigos de España, desde Eta a los golpistas" (ID=222).

\subsection{Favs y retuits}

Los mensajes publicados por Santiago Abascal en su perfil durante el estado de alarma obtuvieron, de promedio 11.250 favs y 5.070 retuits. Los valores medianos fueron 9.165 y 4.525 respectivamente. Se trata de los mensajes que recibieron un respaldo explícito por parte de sus seguidores o que fueron compartidos por estos.

A pesar de ser uno de los perfiles de Twitter con menor número de seguidores de todos los analizados (junto con el de Pablo Casado), el de Santiago Abascal es el que registra mayor grado de interacción con ellos, con diferencia notable con respecto a los mismos registros de sus adversarios políticos.

\section{Gráfico 2: Promedio de favs y retuits de las publicaciones en Twitter de los líderes políticos españoles durante el estado de alarma (del 14 de marzo al 20 de junio)}

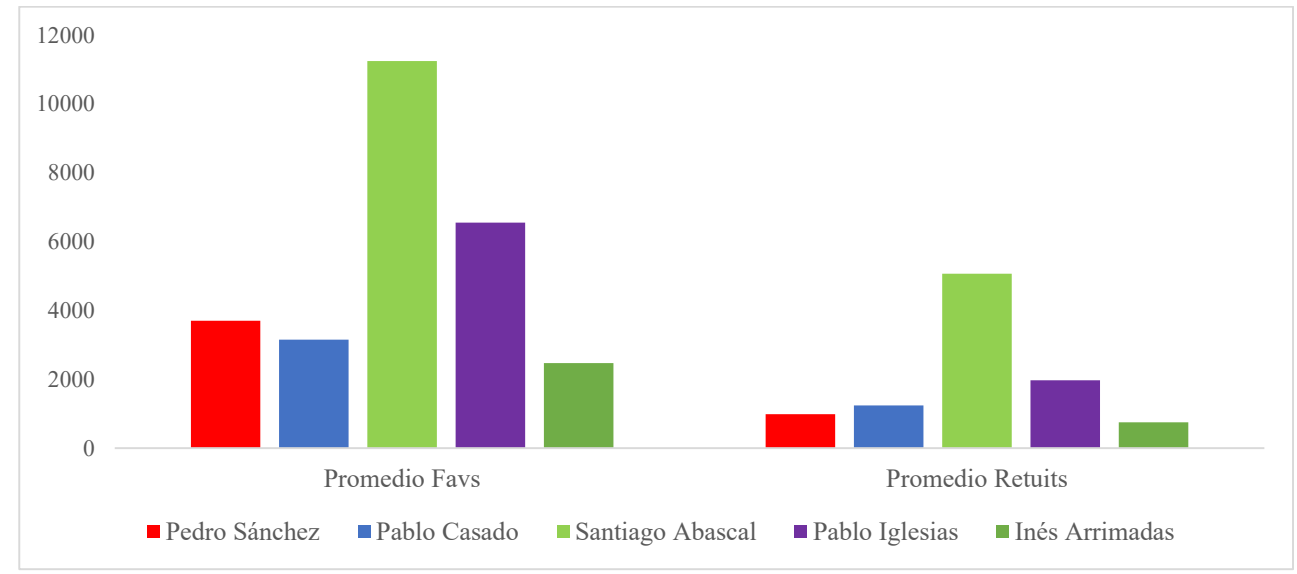

Fuente: Twitter. Elaboración propia

Pablo Iglesias registra unos valores promedio de 6.556 (favs) y 1.972 (retuits) respectivamente; Pedro Sánchez 3.701 (favs) y 988 (retuits); Pablo Casado 3.155 (favs) y 1.241 (retuits); por último, Inés Arrimadas 2.474 (favs) y 751 (retuits).

Santiago Abascal consigue rentabilizar sus mensajes en mayor medida que el resto de los líderes políticos, al menos en lo que respecta a las interacciones en Twitter. Los seguidores del presidente de Vox se muestran mucho más entusiastas a la hora de señalar 
su adhesión por sus mensajes, así como por compartirlos. De hecho, si se toma como base el número de seguidores que su perfil tenía a 15 de mayo (460.984) la ratio de interacciones por cada mil seguidores, de valor promedio, sería de 24,4 en el caso de los favs y de 10,9 en los retuits. Se trata de los registros más altos de los cinco líderes, con una gran diferencia con respecto al resto.

Tabla 2. Ratio de interacciones (favs y retuits) por cada 1.000 seguidores, tomando como base el número de seguidores de las cuentas a 15 de mayo y el promedio de favs y retuits durante el estado de alarma (del 14 de marzo al 20 de junio)

\begin{tabular}{|c|c|c|}
\hline Perfil de Twitter & Favs por cada mil seguidores & Retuits por cada mil seguidores \\
\hline Pedro Sánchez & 2,6 & 0,7 \\
\hline Pablo Casado & 7,0 & 2,7 \\
\hline Santiago Abascal & 24,4 & 10,9 \\
\hline Pablo Iglesias & 2,5 & 0,7 \\
\hline Inés Arrimadas & 3,7 & 1,1 \\
\hline
\end{tabular}

Fuente: Twitter. Elaboración propia

De todos los mensajes lanzados durante el estado de alarma por parte de los cinco líderes en Twitter el que cuenta con un mayor número de favs corresponde a una publicación de Pedro Sánchez del 16 de marzo (75.155 favs y 18.941 retuits) escrito en inglés y en el que responde a la cantante norteamericana Miley Cyrus.

"Spain is coleader in initiatives such as the ACT-Accelerator to achieve equitable access to vaccines, treatments and diagnosis to fight \#COVID19. Ours is a strong commitment, Miley. Unity and multilateral response is the only way forward not to let anyone behind. \#GlobalGoalUnite" (ID=259).

El siguiente mensaje más popular del presidente del gobierno cuenta con 23.375 favs y 4.359 retuits.

En cuanto al resto de líderes los mensajes con mayor número de interacciones son de 63.232 favs y 17.584 retuits (Pablo Iglesias); 54.251 favs y 20.994 retuits (Santiago Abascal); 21.489 favs y 7.878 retuits (Pablo Casado); y 21.846 favs y 1.262 retuits (Inés Arrimadas).

De los diez mensajes que consiguen mayor número de favs en el perfil de Santiago Abascal, siete de ellos tienen que ver con la covid-19 o la gestión del estado de alarma, mientras que tres hacen referencia a otros temas, dos relacionados con el terrorismo y uno con política internacional (Venezuela). La publicación con mayor respaldo, publicada el 14 de marzo, es la que hace referencia a su situación como infectado del virus, en los primeros días de la pandemia. En ella también realiza crítica política al Vicepresidente del gobierno, Pablo Iglesias:

"Permanezco en una habitación de $9 \mathrm{~m}^{2}$ sin salir desde hace varios días, y toda mi familia en casa y sin contacto conmigo respetando la cuarentena. Y veo que el vicepresidente no respeta su propia cuarentena yendo al Consejo de Ministros para prohibirnos salir de casa. Casta." (ID=2) 
Aparte de conseguir el mayor número de favs y retuits de promedio, Santiago Abascal también es el político que alcanza un mayor éxito en cada una de sus publicaciones, ateniéndonos a la respuesta de sus seguidores. En concreto, 75 mensajes obtienen más de 15.001 favs; 57 entre 5.001 a 10.000; 117 entre 5.001 y 10.000 y solo 40 menos de 5.000 .

\section{Gráfico 3: Distribución del número de favs a los mensajes de los líderes políticos españoles durante} el estado de alarma (14 de marzo al 20 de junio)

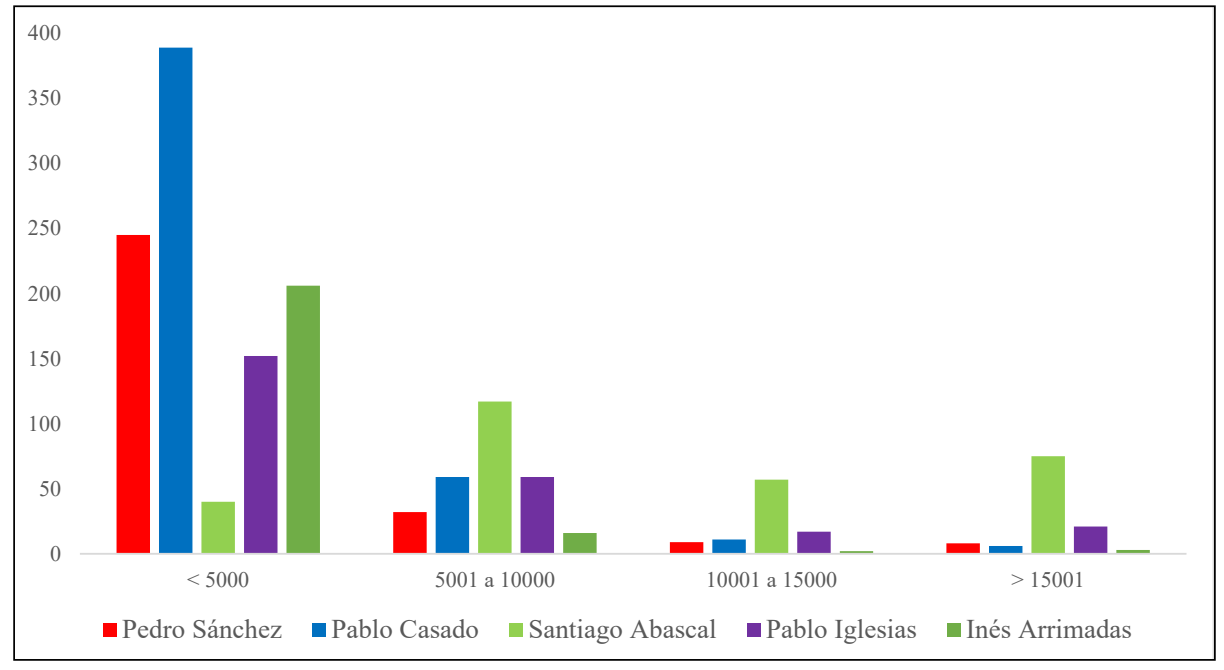

Fuente: Twitter. Elaboración propia

Ninguno de los otros perfiles políticos obtiene unos resultados similares, ya que la mayoría de sus mensajes se concentran en los segmentos de menos de 5.000 favs (Pedro Sánchez: 245; Pablo Casado: 389; Pablo Iglesias: 152; e Inés Arrimadas: 206). En menos proporción se sitúan los mensajes de entre 5.001 y 10.000 (Pedro Sánchez: 32; Pablo Casado: 59; Pablo Iglesias: 59; e Inés Arrimadas: 16). En los segmentos que suponen mayor número de interacciones la diferencia se acentúa todavía más a favor del perfil de Santiago Abascal. Entre 10.001 y 15.000: Pedro Sánchez: 9; Pablo Casado: 11; Pablo Iglesias: 17 e Inés Arrimadas: 2. Más de 15.001 favs: Pedro Sánchez: 8; Pablo Casado: 6; Pablo Iglesias: 21; e Inés Arrimadas: 3.

En términos relativos la distribución muestra más claramente la forma en la que se comportan los seguidores de Abascal, que interactúan de un modo más decidido con su perfil de Twitter. 
Tabla 3. Porcentaje de distribución de los mensajes en función de su número de favs durante el estado de alarma (14 de marzo a 20 de junio)

\begin{tabular}{|l|c|c|c|c|}
\hline Político & 0 a 5.000 & $\mathbf{5 . 0 0 1}$ a 10.000 & $\mathbf{1 0 . 0 0 1}$ a 15.000 & Más de 15.001 \\
\hline Pedro Sánchez & $83,33 \%$ & $10,88 \%$ & $3,06 \%$ & $2,72 \%$ \\
\hline Pablo Casado & $83,65 \%$ & $12,68 \%$ & $1,29 \%$ \\
\hline Santiago Abascal & $13,84 \%$ & $40,48 \%$ & $6,72 \%$ & $25,95 \%$ \\
\hline Pablo Iglesias & $61,04 \%$ & $23,69 \%$ & $8,43 \%$ \\
\hline Inés Arrimadas & $90,74 \%$ & $7,04 \%$ & $0,88 \%$ & $1,32 \%$ \\
\hline
\end{tabular}

Fuente: Twitter. Elaboración propia

\subsection{Crecimiento del perfil}

Otro dato con el que se puede calibrar el éxito de la estrategia comunicativa desarrollada en Twitter durante la crisis del coronavirus y el estado de alarma es la forma en la que ha evolucionado cada uno de los perfiles en cuanto a número de usuarios.

El perfil de Santiago Abascal a 29 de febrero contaba con 371.562 seguidores. Esta cifra lo situaba por detrás de Pablo Iglesias (2.460.342 seguidores), Pedro Sánchez (1.175.269) e Inés Arrimadas (589.720). Por detrás del líder de Vox tan solo se encontraba Pablo Casado (329.100). De hecho, incluso Albert Rivera, a pesar de haberse retirado oficialmente de la política, mantenía un número de seguidores sensiblemente superior (1.174.584).

La estrategia llevada a cabo por el líder de la extrema derecha española en esta red social ha tenido resultados más que evidentes. A 21 de junio el número de seguidores de su perfil había aumentado hasta los 487.263, 115.701 seguidores más (un crecimiento del 31,13\%). Tras el paso del estado de alarma se seguía situando por detrás de los líderes antes mencionados: Pedro Sánchez (1.428.480 seguidores; 253.211 seguidores más), Pablo Iglesias $(2.586 .721 ; 126.379)$ e Inés Arrimadas $(671.850 ; 82.130)$. A pesar de lograr un crecimiento tan importante, las distancias en cuanto a popularidad de los perfiles crecieron con respecto a los de Pedro Sánchez y Pablo Iglesias, reduciéndose exclusivamente con el de Inés Arrimadas.

Al mismo tiempo, a 21 de junio todavía seguía por delante de Pablo Casado (474.778 seguidores; 145.678 seguidores más), si bien la distancia entre ambos perfiles se redujo considerablemente.

De hecho, ni siquiera porcentualmente el aumento experimentado por Santiago Abascal fue el mayor, ya que se vio superado por el de Pablo Casado (44,26\% de seguidores más). 


\section{Gráfico 4: Crecimiento relativo (en \% de número de seguidores), de los perfiles de Twitter de los líderes políticos españoles (del 29 de febrero al 21 de junio)}

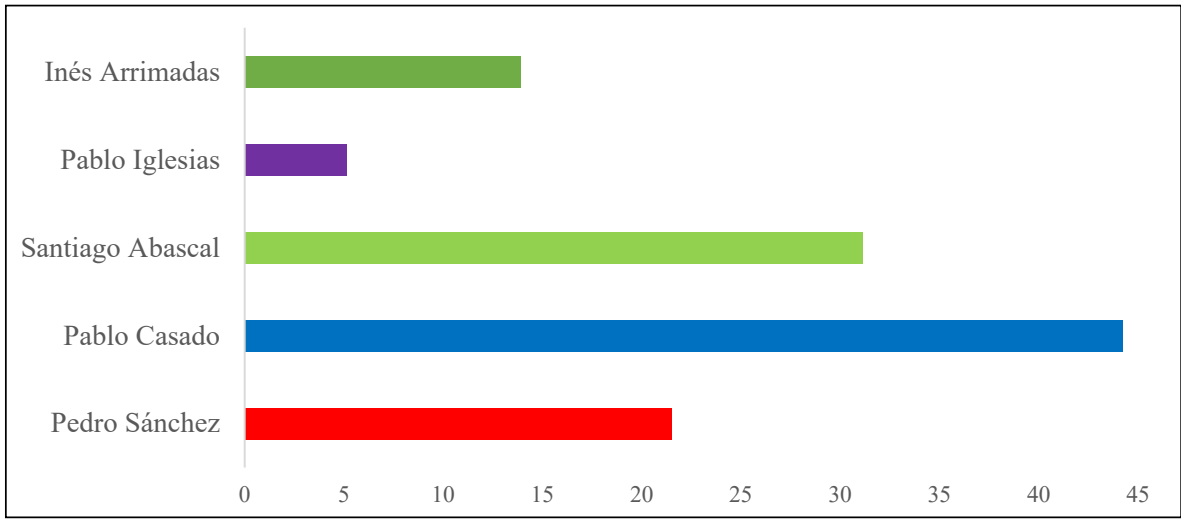

Fuente: Twitter. Elaboración propia

La actividad en Twitter, incluso el éxito obtenido por sus mensajes (a la hora de ser señalados como favoritos o compartidos por sus seguidores) no se traslada, por lo tanto, en un mayor seguimiento de sus perfiles. A pesar de haber encontrado en su audiencia niveles de interacción mucho menores, Pablo Casado rentabiliza mejor su actividad durante el estado de alarma. Incluso Pedro Sánchez y Pablo Iglesias, desde el gobierno, aumentan su distancia con Santiago Abascal en cuanto a número de seguidores en este mismo periodo de tiempo. Sánchez contaba a 21 de junio con 941.217 seguidores más que Abascal (a 29 de febrero la diferencia era de 803.707). En lo que respecta a Pablo Iglesias la diferencia tras el estado de alarma es de 2.099 .458 seguidores (2.088.780 a 29 de febrero).

\subsection{Temas abordados}

Para realizar esta investigación se establecieron siete grandes categorías, a través de las que poder clasificar las temáticas de los mensajes publicados por el perfil de Santiago Abascal, correspondientes a aquellos temas que agruparan más de diez publicaciones a lo largo del periodo de análisis. 
Tabla 4. Categorización temática de los mensajes publicados por Santiago Abascal en su perfil oficial de Twitter durante el primer estado de alarma en España provocado por el coronavirus (14 de marzo - 21 de junio de 2020).

\begin{tabular}{|l|l|}
\hline Categoría & Descripción \\
\hline Pugna política & Mensajes caracterizados por las controversias con otros partidos políticos o con el gobierno. \\
\hline Medios de comunicación & Relacionados con los medios de comunicación. \\
\hline Promoción & $\begin{array}{l}\text { Mensajes que hacen referencia al propio partido y que tienen por objetivo el proselitismo de sus ideas, va- } \\
\text { lores, etc. }\end{array}$ \\
\hline Otros & $\begin{array}{l}\text { Se agrupa en esta categoría temáticas diversas que por separado no reunieran un número mínimo de diez } \\
\text { publicaciones. }\end{array}$ \\
\hline Inmigración & Mensajes que hacen referencia a la llegada o permanencia en España de personas migrantes \\
\hline Economía & Temas económicos \\
\hline Internacional & Asuntos relacionados con la política internacional \\
\hline
\end{tabular}

Fuente: Elaboración propia

El primer aspecto que llama la atención en este apartado es que durante el primer estado de alarma, la gran mayoría de los 289 mensajes publicados por Santiago Abascal en su perfil de Twitter ( $n=175$, lo que supone un 60,55\%) se encuadran en el apartado de pugna política. La actividad del líder de Vox se centró en la crítica a sus adversarios políticos, en especial al gobierno español, tanto al presidente Pedro Sánchez como a su vicepresidente segundo, Pablo Iglesias, líderes respectivamente del PSOE y de Unidas Podemos. El tono general es muy crítico con la gestión del gobierno y prácticamente solo en el primer día del estado de alarma (14 de marzo) se transmite un tono conciliador o colaborador con el gobierno. No obstante, a pesar de ese tono, también en esos mensajes se incluyen duras críticas a los socios del gobierno o a aquellos partidos que apoyaron la investidura.

"Si Sánchez necesita los votos de VOX para decretar el estado de alarma, unificar gestión de la crisis y poner todos los servicios del Estado a combatir la pandemia y sus efectos económicos y sociales, puede contar con ello y escapar del miserable chantaje comunista y separatista" (ID=5, 14 de marzo) 
Gráfico 5: Distribución temática de las publicaciones en Twitter de Santiago Abascal durante el primer estado de España en España a causa de la pandemia del coronavirus (14 de marzo - 20 de junio de 2020)

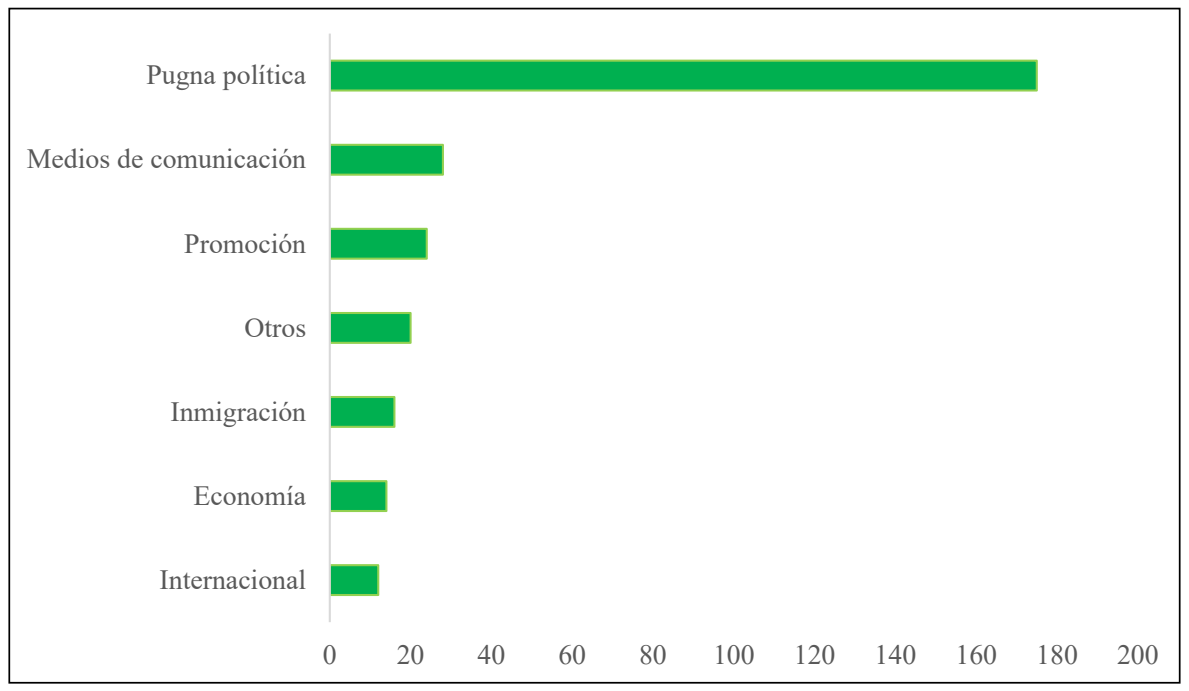

Fuente: Twitter. Elaboración propia

Este tipo de mensajes se mantienen a lo largo de todo el periodo analizado, si bien se intensifican con motivo de la celebración de la llamada "Caravana por España y su libertad” que el partido convocó en todas las capitales de provincia el sábado 23 de mayo.

El siguiente bloque temático lo ocuparían los mensajes relacionados con los medios de comunicación (n=28, 9,7\%), especialmente duro con algunos de ellos, como es el caso de El País. Hacia la propiedad del grupo PRISA, al que pertenece el mencionado diario, dirige algunas duras críticas, personificadas en Ana Patricia Botín:

“Señora Botín, 4 millones de españoles empezamos a estar hartos de que el medio de comunicación cuya propiedad comparte con otros multimillonarios, se dedique a insultarnos, estigmatizarnos y a manipular de manera sistemática". (ID=162, 14 de mayo).

El resto de temáticas merecen una atención mucho menor en forma de publicaciones, asuntos como promoción de sus propias ideas (24 mensajes), inmigración (20 mensajes), economía (14) o internacional (12) quedan relegados, por lo tanto, ante el principal objeto durante el periodo analizado, que fue la crítica al gobierno. Llama la atención en esta última categoría (internacional), el apoyo explícito a gobiernos como el de Orban en Hungría (ID=38, 1 de abril) o el de Trump, en plenas protestas del movimiento Black Lives Matter (ID=226, 30 de mayo). En otros mensajes relaciona la situación de Venezuela con el gobierno español (ID=206, 26 de mayo).

En el apartado de otros (20 mensajes) se incluyen algunos relacionados con el patriotismo (7 mensajes), las Fuerzas de Seguridad (5 mensajes), el terrorismo (4 mensajes), la religión, coincidiendo con la celebración de la semana santa (3) o las informaciones relacionadas con su persona (un mensaje), tras haber superado la covid-19 en marzo. 
Sorprende que en unos momentos tan singulares, en los que se prodigaron mensajes de ánimo a diferentes colectivos, este tipo de mensajes son prácticamente inexistentes en los tuits publicados por Santiago Abascal. Tan solo se hacen referencias explícitas al pueblo ("En España, al final, siempre ha reaccionado el pueblo cuando han fallado las instituciones", ID=1, 14 de marzo) o a las Fuerzas de Seguridad del Estado, como en el mensaje de felicitación por el aniversario de la Guardia Civil (ID=154, 13 de mayo). El resto de líderes políticos sí publicaron varios mensajes de apoyo o agradecimiento a colectivos como el de sanitarios, por ejemplo haciéndose eco de los homenajes que se les tributaron durante buena parte del confinamiento, en forma de aplausos de la ciudadanía.

\subsection{Tipo de lenguaje}

El lenguaje utilizado destaca por su contundencia. En 175 mensajes (el 60\% del total) se utilizan elementos agresivos, irrespetuosos o descalificadores. Predominan los mensajes con descalificaciones e incluso con acusaciones de gravedad contra los adversarios políticos. Hasta en once publicaciones, por ejemplo, utiliza la expresión "gobierno criminal", refiriéndose al gobierno español, una de ellas incluso como hashtag, \#Gobiernocriminal (ID=201, 25 de mayo). Asimismo, afirma que "estamos en manos de criminales" (ID=136, 7 de mayo) o "estamos al borde de una dictadura criminal" (ID=37, 1 de abril).

Al presidente, Pedro Sánchez, lo tilda de "embustero" (ID=145, 10 de mayo). En el caso del vicepresidente segundo, Pablo Iglesias, además de calificarlo hasta en tres ocasiones como "vicepandemias" (ID=212, 27 de mayo; ID=222, 28 de mayo; e ID=285, 19 de junio) llega también a llamarlo "fanfarrón de poca monta" (ID=283, 6 de junio), "empleado de las narcodictaduras" (ID=13, 17 de marzo), "aliado de narco-tiranías asesinas" (ID=155, 13 de mayo) o le acusa de actuar como un "matón y como un criminal" (ID=180, 19 de mayo).

Son habituales igualmente los adjetivos calificativos contra los grupos que apoyan al gobierno de coalición. Destacan las referencias al terrorismo de ETA: "Si pactan las leyes laborales de los españoles con la banda... ¿Por qué no iban a dar un buen trato a sus secuestradores y asesinos que estaban presos? Ya nada sorprende". (ID=252, 10 de junio), tuit publicado tras el acuerdo con el grupo parlamentario de EH Bildu para la derogación de la reforma laboral. Estas acusaciones también se hacen extensivas a todo el Congreso: "El Congreso se ha convertido en una institución secuestrada por comunistas, separatistas y proetarras. El vicepresidente se permite decir allí que VOX desea un golpe de Estado. Y no pasa nada. Cuando hoy VOX ha llamado 'golpista' a ERC... Batet lo retira del Diario de Sesiones". (ID=255, 11 de junio).

Este tipo de lenguaje no solo se utiliza contra los adversarios políticos, también los medios de comunicación son objeto de descalificaciones, con el uso, hasta en cuatro ocasiones del epíteto "lacayos". En el caso del diario "El País", le cambia incluso el nombre a “Lo País", definiéndolo como “El Diario Dependiente de Las Oligarquías" (ID=160, 14 de mayo).

Los términos descalificativos empleados por Santiago Abascal no encuentran paralelismos en ninguno de los otros líderes políticos españoles. Ni siquiera resultan expresiones habituales en Pablo Casado o Inés Arrimadas que, a pesar de ser críticos con el gobierno, no recurren en ningún caso a expresiones o términos de esta naturaleza. Se trata, por tanto, de un rasgo característico exclusivo de la comunicación del líder de Vox. 


\section{Discusión y conclusiones}

Una primera cuestión que aflora a la vista de los resultados encontrados tiene que ver con el efecto de los perfiles de Twitter en la política real. Si se analizan el nivel de seguimiento de los perfiles de los partidos durante la última campaña electoral y los resultados que estos obtuvieron, no se establece ningún tipo de relación posible. El coeficiente de correlación de Pearson $(-0,007)$ muy cercano a 0 y la línea de tendencia prácticamente plana así lo atestiguan.

Tabla 4. Correlación entre el número de seguidores de los partidos políticos españoles a 1 de noviembre y el número de votos obtenido en las elecciones del 10 de noviembre de 2019

\begin{tabular}{|l|c|c|}
\hline Partido & Número de seguidores & Votos elecciones \\
\hline PSOE & 711.733 & 6.792 .199 \\
\hline PP & 727.559 & 5.047 .040 \\
\hline Vox & 317.167 & 3.656 .979 \\
\hline Unidas Podemos & 1.415 .920 & 3.119 .364 \\
\hline Ciudadanos & 519.204 & 1.650 .318 \\
\hline
\end{tabular}

Fuente: Twitter / Ministerio del Interior. Elaboración propia

Resulta preciso señalar que el número de seguidores de una cuenta de estas características, tanto la de un partido como la de un líder político, no puede identificarse de modo automático con simpatizantes o votantes. Entre los seguidores de una cuenta de tipo político pueden encontrarse desde simpatizantes de otros países, hasta adversarios, pasando por periodistas u otro tipo de personas interesadas e incluso bots $\mathrm{u}$ otros mecanismos utilizados para dotarle de una mayor visibilidad o actividad a dichos perfiles. A pesar de que la influencia de los bots ha quedado al margen de esta investigación de forma intencionada, se plantea como una interesante línea de trabajo futura, con la que se pueda evaluar la dimensión real que este tipo de perfiles representa en la interacción con los principales actores de la política española.

El estudio demuestra que del nivel de interacción con los mensajes emitidos no se puede extrapolar una garantía de éxito para el crecimiento o popularidad de determinado perfil en las redes sociales. Los seguidores de Santiago Abascal se manifiestan mucho más entusiastas que los del resto de líderes, a la hora de demostrar sus preferencias por esta opción política. Pero esa actividad no demuestra una mayor adhesión por esos mensajes más allá de los sectores ya convencidos. Los mensajes tienden, por lo tanto, a la endogamia y a la alimentación de los propios nichos o sectores más convencidos a través de los filtros burbuja (Pariser, 2011).

En relación con los objetivos planteados en esta investigación se pueden establecer las siguientes conclusiones.

O1: La actividad del perfil de Twitter de Santiago Abascal durante el estado de alarma fue similar a la del resto de líderes políticos españoles. De hecho, resultó muy inferior a la de otro político de la oposición (Pablo Casado) y se mantuvo en un umbral semejante a la de Pedro Sánchez. No obstante, los mensajes lanzados durante la campaña en el perfil de Santiago Abascal de Twitter sí se confirman como los más populares de todos los de los líderes políticos españoles. Esta popularidad se entiende, dentro de las redes sociales, como las interacciones (favs y retuits) logradas entre sus seguidores. Este dato revela que los simpatizantes de Vox se manifiestan como los más entusiastas y activos en esta red social. 
Santiago Abascal no rentabilizó del mismo modo que otros líderes, especialmente Pablo Casado, su actividad en redes durante la crisis. A pesar del entusiasmo demostrado por sus seguidores, el nivel de crecimiento de la cuenta se sitúa por debajo del perfil de Pablo Casado, que fue quien rentabilizó mejor en Twitter la crisis de la covid-19.

O2: La comunicación en Twitter de Santiago Abascal durante el primer estado de alarma en España se caracterizó por la utilización de esta coyuntura para ahondar en su crítica al gobierno de España, objetivo al que dirigió la mayoría de sus mensajes. Esta crítica, además, destaca por su agresividad, con un lenguaje tendente a las descalificaciones, especialmente a los miembros del gobierno y a los partidos que lo apoyan. Una característica que lo distingue del resto de líderes políticos.

Como conclusión final, queda demostrado que, a pesar de que la crisis de la covid-19 ha supuesto una oportunidad para que los mensajes de Vox, y con ellos el liderazgo de Santiago Abascal, se abran camino, su alcance resulta limitado. El líder del partido ha utilizado la crisis generada por el coronavirus, especialmente durante el estado de alarma, para profundizar en sus críticas al gobierno y tratar de alcanzar un mayor número de adeptos. El alcance de estos objetivos en redes sociales puede considerarse como muy matizado, si se tiene en cuenta la forma en la que ha evolucionado el número de seguidores en cada uno de los perfiles.

Twitter se comporta por lo tanto como una imagen deformada de la sociedad, en la que los simpatizantes de Santiago Abascal proceden de un modo mucho más activo, pero cuyo efecto real no parece responder a los mismos patrones.

\section{Agradecimientos}

Este artículo ha sido traducido al inglés por Brian O'Halloran.

\section{Referencias bibliográficas}

Aba, A. (2011). El estado de alarma en España. Teoría y Realidad Constitucional, 28. 305-334. DOI: 10.5944/trc.28.2011.6961

Acha-Ugarte, B. (2018). The Far Right in Western Europe: "From the Margins to the Mainstream" And Back?. Cuadernos Europeos de Deusto, 59. 75-97. DOI: 10.18543/ced-59-2018pp75-97

Agnew, J. (2020). American "Populism" and the Spatial Contradictions of US Government in the Time of COVID-19. Geopolitica(s). Revistas de estudios sobre espacio y poder, 11 (número especial). 15-23. DOI: 10.5209/geop.69018

Ahmed, R. y Pisoiu, D. (2020). Uniting the far right: how the far-right extremist,New Right, and populist frames overlap on Twitter-a German case study. European Societies. October 2020. DOI: 10.1080/14616696.2020.1818112

Åkerlund, M. (2020). The importance of influential users in (re)producing Swedish far-right discourse on Twitter. European Journal of Communication, 35(6), 613-628. DOI: 10.1177/0267323120940909

Akkerman, T.; De-Lange, S. L. y Rooduijn, M. (2016). "Into the mainstream? A comparative analysis of the programmatic profiles of radical right-wing populist parties in Western Europe over time”. En: Akkerman, T.; De-Lange, S.; Rooduijn, M. Radical right-wing populist parties in Europe. Into the mainstream?. 53-69. New York: Routledge

Antón-Mellón, J. y Hernández-Carr, A. (2016). El crecimiento electoral de la derecha radical populista en Europa: parámetros ideológicos y motivaciones sociales. Política y Sociedad, 53(1). 17-28. DOI: 10.5209/rev_POSO.2016.v53.n1.48456 
Arroyo, J. (2020). Coronavirus: la OMS declara la pandemia a nivel mundial por Covid-19. Redacción médica, 11 de marzo. Disponible en: http://bit.ly/2OuGbnq

Bastos, M. T. y Mercea, D. (2019). The Brexit Botnet and User-Generated Hyperpartisan News. Social Science Computer Review, 37(1). 38-54. DOI: 10.1177/0894439317734157

Bennett, S. (2019). “Standing up for 'real people' UKIP, the Brexit, and discursive strategies on Twitter". En: Zienkowski, J. y Breeze, R. Imaging the peoples of Europe. Populist discourses across the political spectrum. 229-256. Amsterdam: John Benjamins. DOI: 10.1075/dapsac.83.10ben

Berman, R. y Katona, Z. (2019). Curation Algorithms and Filter Bubbles in Social Networks. Marketing Science, 39. 296-316. DOI: $10.1287 / \mathrm{mksc} .2019 .1208$

Berti, C. (2020). Right-wing populism and the criminalization of sea-rescue NGOs: the 'Sea-Watch 3' case in Italy, and Matteo Salvini's communication on Facebook. Media Culture \& Society. September 2020. 0163443720957564. DOI: 10.1177/0163443720957564

Bialasiewicz, L. y Stallone, S. (2020). Focalizing new-Fascism: Right politics and integralisms in contemporary Italy. Environment and Planning C-Politics and Space, 38(3). 423-442. DOI: 10.1177/2399654419871303

Boulianne, S.; Koc-Michalska, K. y Bimber, B. (2020). Right-wing populism, social media and echo chambers in Western democracies. New media \& Society, 22(4). 683-699. DOI: 107.171/1774/61144614448418918989933983

Caiani, M. (2019). The rise and endurance of radical right movements. Current sociology, 67(6). 918-935. DOI: $10.1177 / 0011392119868000$

Campos-Domínguez, E. (2017). Twitter y la comunicación política. El profesional de la información, 26(5). 785-793. DOI: 10.3145/ epi.2017.sep.01

Cheung-Blunden, V. (2020). Situational insecurity versus entrenched ideologies as the source of right-wing voters' anti-migrant sentiment on both sides of the Atlantic. Journal of Applied Social Psichology, marzo. DOI: 10.1111/jasp.12663

Conde, M. (2020). Brazil in the Time of Coronavirus. Geopolítica(s). Revistas de estudios sobre espacio y poder, 11 (especial). 239249. DOI: $10.5209 /$ geop. 69349

Cooper, S. (2006). Test Case: A Preview of Disruption. Harvard Business Review. Disponible en http://bit.ly/3r8BAVN

Costa-Sánchez, C. y López-García, X. (2020). Comunicación y crisis del coronavirus en España. Primeras lecciones. El profesional de la información, 29(3). DOI: 10.3145/epi.2020.may.04

Cruz, M. (2020). Pablo Iglesias acusa a Vox de “querer dar un golpe de Estado" pero "no atreverse”. El Mundo, 28 de mayo. Disponible en https://bit.ly/394CfkH

Darius, P. y Stephany, F. (2019). "Hashjacking” the Debate: Polarisation Strategies of Germany's Political Far-Right on Twitter. Social Informatics, Socioinfo 2019, 11864. 298-308. DOI: 10.1007/978-3-030-34971-4_21

Eatwell, R. (2007). Hacia un nuevo modelo de liderazgo carismático de derecha. En: Simón, M. Á. La extrema derecha en Europa desde 1945 a nuestros días. 19-38. Madrid: Tecnos 
Edo, A.; Giesing, Y.; Öztunc, J. y Poutvaara, P. (2019). Immigration and electoral support for the far-left and the far-right. European Economic Review, 115. 99-143. DOI: 10.1016/j.euroecorev.2019.03.001

EFE (2020). Vox acusa a Sánchez de presidir un Gobierno "ilegítimo" basado en la mentira. La Vanguardia, 7 de enero. Disponible en http://bit.ly/2PeTJng

EFE (2020b). Twitter suspende la cuenta de Vox por incitación al odio. 20 minutos, 22 de enero. Disponible en http://bit.ly/3r7ZMrc

Enli, G. (2017). Twitter as arena for the authentic outsider: exploring the social media campaigns of Trump and Clinton in the 2016 US presidential election. European Journal of Communication, 32(1). 50-61. DOI: 10.1177/0267323116682802

Europa Press (2019). Abascal defiende el veto a medios de comunicación y los acusa de una "demonización" de Vox que puede generar violencia. Europa Press, 7 de noviembre. Disponible en http://bit.ly/2NG5AdS

Europa Press (2020). Vox: “Todos los enemigos de España van a formar parte de este gobierno”. Europa Press, 7 de enero. Disponible en http://bit.ly/3rbYP10

Eurostat (2020). Individuals using the internet for participating in social networks. Disponible en http://bit.ly/2Pfvln2

Evolvi, G. (2019). Emotional Politics, Islamophobic Tweets. The Hashtags \#Brexit and \#chiudiamoiporti. Partecipazione e Conflitto, 12(3). 871-897. DOI: 10.1285/i20356609v12i3p871

Ferreira, C. (2019). Vox como representante de la derecha radical en España: un estudio sobre su ideología. Revista Española de Ciencia Política, 51, 73-98. DOI: 10.21308/recp.51.03

Francia, P. L. (2017). Free Media and Twitter in the 2016 Presidential Election: The Unconventional Campaign of Donald Trump. Social Science Computer Review, 36(4). 440-455. DOI: 10.1177/0894439317730302

Froio, C. \& Ganesh, B. (2019). The transnationalisation of far right discourse on Twitter. European Societies, 21(4). 513-539. DOI: $10.1080 / 14616696.2018 .1494295$

Frommer, F. (2011). El pensamiento PowerPoint. Barcelona: Ediciones Península

Gallego, F. (2017). El Frente Nacional francés. De la reagrupación de la extrema derecha a la alternativa nacional-populista (19722014). Tiempo devorado. Revista de Historia Actual, 4(1). 5-38. Disponible en http://bit.ly/2OS2RhS

Gould, R. (2019). Vox España and Alternative für Deutschland: Propagating the Crisis of National Identity. Genealogy 3(4). 64. DOI: $10.3390 /$ genealogy3040064

Groshek, J. y Koc-Michalska, K. (2017). Helping populism win? Social media use, filterbubbles, and support for populist presidential candidates in the 2016 US election campaign. Information, Communication \& Society, 20(9). 1389-1407. DOI: 10.1080/1369118X.2017.1329334

Gruchola, M. y Stawek-Czochra, M. (2021). "The culture of fear" of inhabitants of EU countries in their reaction to the COVID-19 pandemic - A study based on the reports of the Eurobarometer. Safety Science, 135. 105140. DOI: 10.1016/j.ssci.2020.105140

Hansen, M. A. y Clemens, Jennifer L. (2019). What to expect when you're electing: the relationship between far-right strength and citizenship policy in Europe. Comparative European Politics, 17(5). 673-695. DOI: 10.1057/s41295-018-0120-7 
Howard, P. N.; Woolley, S. y Calo, R. (2018). Algorithms, bots, and political communication in the US 2016 election: The challenge of automated political communication for election law and administration. Journal of Information Technology \& Politics, 15(2). 81-93. DOI: 10.1080/19331681.2018.1448735

Hutchins, R. D. y Halikiopoulou, D. (2019). Enemies of liberty? Nationalism, immigration, andthe framing of terrorism in the agenda of the Front National. Nations and Nationalism, 26(1). 67-84. DOI: 10.1111/nana.12555

IMF (2020). World Economic Outlook, April 2020: The Great Lockdown. Disponible en http://bit.ly/3r28V4w

Johns Hopkins (2021). Coronavirus Resource Center. Disponible en: http://bit.ly/3qpcdi6

Junta de Andalucía (2018). Elecciones Parlamento de Andalucía 2018. Resultados definitivos. Disponible en http://bit.ly/3r290VS Keddell, E. y Beddoe, L. (2020). The tyranny of distance: The social effects and practice adaptations resulting from Covid-19 lockdown rules. Aotearoa New Zealand Social Work, 32(2). 41-45. DOI: 10.11157/anzswj-vol32iss2id741

Kissas, A. (2019). Performative and ideological populism: The case of charismatic leaders on Twitter. Discourse \& Society, 31(3). 268-284. DOI: 10.1177/0957926519889127

Kuman, V.; Doshi, K. U.; Khan, W. H. y Rathore, A. S. (2020). COVID-19 pandemic: mechanism, diagnosis, and treatment. Journal of Chemical Technology and Biotechnology, 96(2). 299-308. DOI: 10.1002/jctb.6641

La Razón (2019). Vox no se reunirá con Sánchez mientras negocie con “los enemigos de España”. La Razón, 12 de diciembre. Disponible en http://bit.ly/2QjrGUk

Latif, A. A. y Mukaratirwa, S. (2020). Zoonotic origins and animal hosts of coronaviruses causing human disease pandemics: A review. Onderstepoort Journal of Veterinary Research, 87(1). a1895. DOI: 10.4102/ojvr.v87i1.1895

Lázaro, F. (2014). Vidal-Quadras y Abascal toman las riendas de Vox apostando por la "regeneración” y la unidad de España. El Mundo, 8 de marzo.

Disponible en https://bit.ly/3rctqeJ

Marcos, J. (2020). El PSOE denuncia ante la Fiscalía a Vox por difundir bulos. El País, 16 de abril. Disponible en http://bit. ly/38Y4ce3

Matakos, A.; Tu, S. y Gionis, A. (2020). Tell me something my friends do not know: diversity maximization in social networks. Knowledge and Information Systems, 62. 3697-3726. DOI: 10.1007/s10115-020-01456-1

Michailidou, A. (2017). “Twitter, Public Engagement and the Eurocrisis: More than an Echo Chamber?” En: Barisione, M. y Michailidou, A. Social Media and European Politics. 241-266. London: Palgrave Macmillan. DOI: 10.1057/978-1-137-59890-5_11

Ministerior del Interior (2020). Consulta de Resultados electorales. Disponible en http://bit.ly/3s7vgiA

Mondon, A. y Winter, A. (2019). Whiteness, populism and the racialisation of the working class in the United Kingdom and the United States. Identities. Global studies in Culture and Power, 26(5). 510-528. DOI: 10.1080/1070289X.2018.1552440

Moreno, J. (2020). The Iron Triangle of Urban Entrepreneurialism: The Political Economy of Urban Corruption in Spain. Antipode, 52(5). 1351-1372. DOI: 10.1111/anti.12637 
Nayak, J.; Mishra, M.; Naik, B.; Swapnarekha, H.; Cengiz, K. y Shanmuganathan, V. (2021). An impact study of COVID-19 on six different industries: Automobile, energy and power, agriculture, education, travel and tourism and consumer electronics. Expert Systems. 1-32. DOI: 10.1111/exsy.12677

Norris, P. (2002). Democratic Phoenix. Reinventing Political Activism. Cambridge: Cambridge University Press

Olesky, T.; Wnuk A.; Maison, D. y Lys, A. (2021). Content matters. Different predictors and social consequences of general and government-related conspiracy theories on COVID-19. Personality and Individual Differences, 168. 110289. DOI: 10.1016/j. paid.2020.110289

Ortega Dolz, P. y González, M. (2020). Tormenta política tras declarar un general que la Guardia Civil trabaja para minimizar bulos contrarios al Gobierno. El País, 20 de abril. Disponible en http://bit.ly/314v0Fe

Ott, B. L. (2017). The age of Twitter: Donald J. Trump and the politics of debasement. Critical Studies in Media Communication, 34(1). 59-68. DOI: 10.1080/15295036.2016.1266686

Padovani, C. (2018). Lega Nord and Anti-Immigration ism: The Importance of Hegemony Critique for Social Media Analysis and Protest. International Journal of Communication, 12. 3553-3579. Disponible en http://bit.ly/3qH8UCK http://bit.ly/3qH8UCK

Pariser, E. (2011). The Filter Bubble. What the Internet is hiding from you. New York: The Pinguin Press.

Pérez-Curiel, C. (2020). Trend towards extreme right-wing populism on Twitter. An analysis of the influence on leaders, media and users. Communication \& Society, 33(2). 175-192. DOI: 10.15581/003.33.2.175-192

Quintero, L. F; Alonso, M. (2014). Nace Vox, el partido político de Santiago Abascal y Ortega Lara. Libertad Digital, 14 de enero. Disponible en http://bit.ly/313Q92a

Rinken, S. (2019). “Actitudes ante la inmigración y comportamiento electoral”. En: Arango, J.; Mahía, R.; Moya, D. y Sánchez-Montijano, E. "Inmigración, elecciones y comportamiento político". Anuario CIDOB de la inmigración 2019. 68-81. Barcelona: CIDOB, pp. 68-81. DOI: 10.24241/AnuarioCIDOBInmi.2019.68

Rivas-de-Roca, R.; García-Gordillo, M. y Bezunartea-Valencia, O. (2020). The far-right's influence on Twitter during the 2018 Andalusian elections: an approach through political leaders. Communication \& Society, 33(2). 227-242. DOI: 10.15581/003.33.2.227-242

Rodríguez-Andrés, R. (2018). Trump 2016: ¿presidente gracias a las redes sociales?. Palabra clave, 21(3). 831-859. DOI: 10.5294/ pacla.2018.21.3.8

Rodríguez-Jiménez, J. L. (2006). De la vieja a la nueva extrema derecha (pasando por la fascinación del fascismo). Historia Actual Online, 9. 87-99. Disponible en http://bit.ly/3tGeWWj

Roupaklias, S. y Chletsos, M. (2020). Immigration and far-right voting: evidence from Greece . Annals of Regional Science, abril. DOI: $10.1007 /$ s00168-020-00996-2

Saladino, V.; Algeri, D. y Auriemma, V. (2020). The Psychological and Social Impact of Covid-19: New Perspectives of Well-Being. Frontiers in Psychology, 11. 577684. DOI: 10.3389/fpsyg.2020.577684

Sampietro, A. y Sánchez-Castillo, S. (2020). La promoción de la imagen política en Instagram: un estudio del perfil personal de Santiago Abascal (Vox) en 2018. Communication \& Society, 33(1). 169-184. DOI: 10.15581/003.33.1.169-184 
Serrano, P. (2013). La comunicación jibarizada. Barcelona: Ediciones Península

Statista (2020). Leading countries based on number of Twitter users as of April 2020. Disponible en http://bit.ly/3tL0ITU

Tollefson, J. (2020). Five ways that Trump is undermining environmental protections under the cover of coronavirus. Nature, 28 de abril. DOI: 10.1038/d41586-020-01261-4 Disponible en go.nature.com/392t4Bm

Tomkins, L. (2020). Where is Boris Johnson? When and why it matters that leaders show up in a crisis. Leadership, 14 de mayo. DOI: $10.1177 / 1742715020919657$

Turnbull-Dugarte, S. (2019). Explaining the end of Spanish exceptionalism and electoral support for Vox. Research and Politics, 6(4). 1-8. DOI: $10.1177 / 2053168019851680$

Usher, J.; Dondio, P. y Morales, L. (2019). The Political Power of Twitter. En: ACM International Conference on Web Intelligence (WI 2019). 326-331. https://doi.org/10.1145/3350546.3352541

Van-der-Brug, W. y Fennema, M. (2003). Protest or mainstream? How the European anti-immigrant partiesdeveloped into two separate groups by 1999. European Journal of Political Research, 37(1). 77-102. DOI: 10.1111/1475-6765.00074

Van-der-Walt, S. (2019). Populism and the yearning for closure: From economic to cultural fragility. European Journal of Social Theory. 1 de agosto. DOI: $10.1177 / 1368431019866338$

Virdee, S. y McGeever, B. (2017). Racism, Crisis, Brexit. Ethnic and Racial Studies, 41(10). 1802-1819. DOI: $10.1080 / 01419870.2017 .1361544$

VOX (2020). Vox, la alternativa social y patriótica frente al consenso progre. Disponible en http://bit.ly/3tHax5A

Whine M (2012) Trans-European trends in right-wing extremism. In: Mammone A, Godin E and Jenkins B (eds) Mapping the Radical Right in Contemporary Europe: From Local to Transnational. Abingdon and New York: Routledge, pp. 317-333

White, A. (2020). Men and COVID-19: the aftermath. Postgraduate Medicine, 132. 18-27. DOI: 10.1080/00325481.2020.1823760

Williams, G. (2014). This scientist has a plan to stop the world's next pandemic. Wired, 14 mayo. Disponible en http://bit. ly/31105wb

Zuk, P. y Toporowski, J. (2020). Capitalism after communism: The triumph of neoliberalism, nationalist reaction and waiting for the leftist wave. Economic and Labour Relations Review, abril. DOI: 10.1177/1035304620911121 